\title{
BMJ Open Term admissions to neonatal units in England: a role for transitional care? A retrospective cohort study
}

\begin{abstract}
Cheryl Battersby, ${ }^{1}$ Stephanie Michaelides, ${ }^{2}$ Michele Upton, ${ }^{3}$ Janet M Rennie, ${ }^{4}$ On behalf of the Jaundice Working Group of the Atain (Avoiding Term Admissions Into Neonatal units) programme, led by the Patient Safety team in NHS Improvement
\end{abstract}

To cite: Battersby C, Michaelides S, Upton M, et al. Term admissions to neonatal units in England: a role for transitional care? A retrospective cohort study. BMJ Open 2017;7:e016050. doi:10.1136/ bmjopen-2017-016050

- Prepublication history and additional material are available. To view these files please visit the journal online(http://dx.doi. org/10.1136/bmjopen-2017016050).

Received 26 January 2017 Revised 5 April 2017 Accepted 5 April 2017

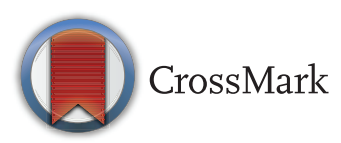

${ }^{1}$ Neonatal Data Analysis Unit, Imperial College London, London, UK

${ }^{2}$ School of Health and Education, Department of Midwifery, Middlesex University, London, UK

${ }^{3}$ Maternity and Newborn, NHS Improvement, London, UK ${ }^{4}$ Neonatal Unit, University College London Hospital, London, UK

Correspondence to Dr. Janet M Rennie; jmr@janetrennie.com

\section{ABSTRACT}

Objective To identify the primary reasons for term admissions to neonatal units in England, to determine risk factors for admissions for jaundice and to estimate the proportion who can be cared for in a transitional setting without separation of mother and baby.

Design Retrospective observational study using neonatal unit admission data from the National Neonatal Research Database and data of live births in England from the Office for National Statistics.

Setting All 163 neonatal units in England 2011-2013. Participants 133691 term babies born $\geq 37$ weeks gestational age and admitted to neonatal units in England. Primary and secondary outcomes Primary reasons for admission, term babies admitted for the primary reason of jaundice, patient characteristics, postnatal age at admission, total length of stay, phototherapy, intravenous fluids, exchange transfusion and kernicterus.

Results Respiratory disease was the most common reason for admission overall, although jaundice was the most common reason for admission from home (22\% home vs $5 \%$ hospital). Risk factors for admission for jaundice include male, born at 37 weeks gestation, Asian ethnicity and multiple birth. The majority of babies received only a brief period of phototherapy, and only a third received intravenous fluids, suggesting that some may be appropriately managed without separation of mother and baby. Admission from home was significantly later (3.9 days) compared with those admitted from elsewhere in the hospital (1.7 days) $(p<0.001)$.

Conclusion Around two-thirds of term admissions for jaundice may be appropriately managed in a transitional care setting, avoiding separation of mother and baby. Babies with risk factors may benefit from a community midwife postnatal visit around the third day of life to enable early referral if necessary. We recommend further work at the national level to examine provision and barriers to transitional care, referral pathways between primary and secondary care, and community postnatal care.

\section{INTRODUCTION}

Separation of mother and baby soon after birth disrupts bonding and the establishment of feeding which is so crucial in the early postnatal period. ${ }^{1}$ The importance of

\section{Strengths and limitations of this study}

The strengths of this study lie in the large national data set from all neonatal units across England.

- Our findings are limited by the retrospective nature of the study; we were unable to explore potential risk factors unavailable or incompletely recorded on the National Neonatal Research Database or Office of National Statistics.

- We may have underestimated the rates of admission for jaundice because the electronic patient record only permits one primary reason for admission but jaundice, weight loss and poor feeding often present together.

family-centred care is well recognised, and where possible, babies should remain with their mothers in an environment where both can be cared for and supported by neonatal and midwifery staff. Transitional care is defined as that delivered within a dedicated transitional care ward or within a postnatal ward where the mother is resident with the baby and providing care. ${ }^{2}$ Transitional care was originally developed in 1982 but is still not widely available. In the years 2012-2013, 58\% of admissions to neonatal units in England were born at term $\geq 37$ weeks gestation (National Data Analysis Unit, NDAU), and while many term admissions are unavoidable, some admissions may be prevented if sufficient resources and expertise are provided in a transitional care setting or where early detection and intervention curtail progression of disease and need for escalation of treatment. Jaundice is an example of a common condition which can be appropriately managed in a transitional care setting for the majority of term babies if detected early. Delay in identification and treatment can result in kernicterus, a devastating lifelong disability arising from bilirubin damage to the brain; this should be an extremely rare event in a managed health care system. ${ }^{34}$ The National 
Institute for Clinical Excellence (NICE) guidance for jaundice in newborn babies under 28 days introduced in $2010^{5}$ recommends the measurement of bilirubin levels urgently (within 6 hours) in all babies more than 24 hours old with suspected or obvious jaundice and the use of a transcutaneous bilirubinometer to measure the bilirubin level for babies born 35 weeks or more and over 24 hours old, highlighting the fact that visual assessment of jaundice is unreliable. However, implementation of these guidelines, particularly in the community, is known to be variable across the country. Furthermore, depending on postnatal age, local referral pathways, available resources and the need for exchange transfusion, babies from the community may be admitted to the postnatal, paediatric ward or neonatal unit; the latter results in separation of mother and baby.

In this study, we aimed to quantify and determine the most common reasons for term admissions to neonatal units in England in 2011-2013. With a focus on jaundice, we determined the risk factors for admission, explored whether these differ between babies admitted from home and hospital and estimated the proportion of term admissions which could have been potentially cared for in a transitional care setting without separation of mother and baby.

\section{METHODS}

We performed a retrospective observational study with data extracted from the National Neonatal Research Database (NNRD) which contains anonymised extracts from neonatal electronic patient records (EPR) from all babies admitted to neonatal units in England. ${ }^{6}$ The NNRD is managed by the NDAU, an independent academic unit based at the Imperial College London, and is approved by the National Research Ethics Service (ref 10/H0803/151) and the Confidentiality Advisory Group of the Health Research Authority (ref 8-05(f)/2010). The NDAU holds Caldicott Guardian permission from the National Health Service (NHS) Trusts to use these data for health services evaluations and approved research. This study, analysed at the national rather than network or unit level, comes under the remit of health services evaluation, and separate ethical approval was not required. ${ }^{7}$ Clinical directors in all English and Welsh neonatal units were made aware of the study and encouraged to contribute through a letter sent on behalf of NHS England.

The following data items for each baby were extracted from the NNRD: primary reason for admission (only one reason was permitted on the database), provider code, gestational age, place of birth, admitted from hospital or community, birth weight, postnatal age at admission (minutes from birth converted to postnatal age in days), fetus number, previous pregnancies, sex, mode of delivery, ethnicity, maternal rhesus status and blood group, length of stay, phototherapy day and intravenous fluid days. Denominator data were provided by the Office of National Statistics (ONS) which contains complete live birth registrations in the UK. Information about newborn babies with jaundice requiring admission to paediatric wards is not available on the NNRD.

\section{Study population}

We included all babies born at term ( $\geq 37$ weeks gestation) and admitted to a neonatal unit in England in years 2011, 2012 and 2013. We included only babies who had at least 1 day of care 'without mother resident' and where location of care was 'neonatal unit'. We excluded babies with congenital anomalies, babies for whom data about their first episode were missing and babies whose first episode of care was in a non-English neonatal unit or whose gestational age was missing.

\section{Analyses}

We calculated the rate of term live births admitted for the primary reason of jaundice, postnatal age at admission, total days of phototherapy, intravenous fluids, exchange transfusion and total length of stay including special, high dependency and intensive care days, as defined by the British Association of Perinatal Medicine. ${ }^{2}$ We sought to determine whether these differed between babies admitted from home versus hospital to gain an understanding of the extent of resource use. We identified risk factors for jaundice by comparing baseline characteristics of babies admitted for jaundice with all live births. Finally, we determined the number of babies with kernicterus, where this diagnosis was coded in the neonatal period. For binary values, we present proportions, and for quantitative values, we present the median and IQR.

Comparisons of proportions and medians were performed using the $\chi^{2}$ test and Mann-Whitney U test, respectively (SAS V.9.3). 'Statistical significance', where discussed, refers to a $5 \%$ significance level.

\section{RESULTS}

\section{Population}

Table 1 shows the breakdown of gestational ages of term live birth babies born in England by year. Around 30\% of term babies were born at 40 weeks, $25 \%$ at 39 weeks, $14 \%$ at 38 weeks and $7 \%$ at 37 weeks gestational age. The total number of term babies admitted to a neonatal unit in England between 2011 and 2013 was 133691, following the exclusion of 2583 babies as per exclusion criteria. This represents around 46000 and $7 \%$ of term babies born in England each year; this has risen from $6.5 \%$ in 2011 to $7.7 \%$ in 2013 (table 1). Over the 3years, a total of 8032 babies, representing around 2700 babies per year, were recorded as admitted for the primary reason of 'jaundice'. This represents around $6 \%$ of term babies admitted to neonatal care and $0.4 \%$ of all term live births in England.

Primary reasons for admission by hospital versus home over the 3 years

A total of 128788 babies (96.3\%) were admitted from hospital; $4858(3.6 \%)$ from home and $45(0.03 \%)$ were in transit or unknown. From within the hospital, the primary 
Table 1 ONS and NNRD data for all term births in England over time 2011-2013

Year (total number of births $\geq 37$ weeks in England as per ONS)

$\begin{array}{llll}2011(n=630376), n & \begin{array}{l}2012(n=640763), \\ n(\%)\end{array} & \begin{array}{l}2013(n=612816), \\ n(\%)\end{array} & \begin{array}{l}\text { Total 2011-2013 } \\ (n=1883955), \\ n(\%)\end{array}\end{array}$

\begin{tabular}{|c|c|c|c|c|}
\hline & (\%) & n (\%) & n (\%) & n (\%) \\
\hline \multicolumn{5}{|c|}{ Gestation (completed weeks) (\% of all term births in England ONS) } \\
\hline 37 & $39116(6.2)$ & $41870(6.5)$ & $42212(6.9)$ & $123198(6.5)$ \\
\hline 38 & $89031(14.1)$ & $91233(14.2)$ & $87517(14.3)$ & $267781(14.2)$ \\
\hline 39 & $153500(24.4)$ & $160370(25.0)$ & $157554(25.7)$ & $471424(25.0)$ \\
\hline 40 & $185401(29.4)$ & $187529(29.3)$ & $178297(29.1)$ & $551227(29.3)$ \\
\hline 42 & $25391(4.0)$ & $23826(3.7)$ & 20307 (3.3) & $69524(3.7)$ \\
\hline$>42$ & $2131(0.3)$ & $1886(0.3)$ & $1530(0.2)$ & $5547(0.3)$ \\
\hline $\begin{array}{l}\text { Term admissions to neonatal } \\
\text { care (NNRD), number of term } \\
\text { babies } \geq 37 \text { weeks (\% of term } \\
\text { births in England ONS) }\end{array}$ & 41045 (6.5) & $45759(7.1)$ & 46887 (7.7) & 133691 (7.1) \\
\hline Other & 30503 (4.8) & $35821(5.6)$ & 38446 (6.3) & 104770 (5.6) \\
\hline Missing & 8222 (1.3) & 7239 (1.1) & $5428(0.9)$ & $20889(1.1)$ \\
\hline
\end{tabular}

NNRD, National Neonatal Research Database; ONS, Office of National Statistics.

reason for admission was missing or 'other' for around $16 \%$ babies. Respiratory disease was the most common primary reason for admission (24\%), followed by infection (18\%), hypoglycaemia $(10 \%)$ and jaundice $(5 \%, 6950$ babies). However, jaundice was the most common reason for admission from home $(22.3 \%, 1082$ babies) (table 2$)$.

\section{Resource use by reason for admission: home versus hospital}

Table 3 reports the median (IQR) total length of stay and special care (SC), high dependency care (HDC) and intensive care (IC) days for the five most common reasons for admission. These were similar for babies admitted from home versus hospital. Median (IQR) total length of stay was 5 (3-7) days. Babies admitted for jaundice were mainly cared for in SC; $99 \%$ of babies received care in SC, $4.9 \%$ required HDC and only $3.6 \%$ required admission to IC. These are not mutually exclusive as babies can be transferred between levels of care during their neonatal stay. These results were similar to those found in babies admitted for hypoglycaemia. While a high percentage of babies $(>90 \%)$ access $\mathrm{SC}$ regardless of the reason for admission, only babies with respiratory disease and asphyxia largely required IC (33.3\% and $53.5 \%$, respectively).

\section{Jaundice: home versus hospital admissions}

Babies were admitted for jaundice at a median (IQR) age of $1.9(0.9-3.4)$ postnatal days, but this was significantly later for babies born at home compared with those born in the hospital (median 3.9 vs 1.7 postnatal days, $\mathrm{p}<0.001)$. For a median (IQR) duration of $1(1-3)$ day(s), $80.6 \%$ received phototherapy and for a median (IQR) duration of 2 (1-3) day(s), 32.8\% received intravenous fluids (table 4). With the exception of postnatal age at admission and rate of kernicterus, there was no statistically significant difference in these parameters between babies admitted from home versus hospital. The rate of exchange transfusion was similar among babies admitted from home and hospital at $1.6 \%$. A total of eight babies were reported to have kernicterus, but the primary reason for admission was not jaundice for one of these cases. One was born in 2011, four in 2012 and three in 2013; four were admitted from home. Although absolute numbers were small, the rate of kernicterus was higher among babies admitted from home $(0.28 \%)$ versus hospital $(0.06 \%)$. Four were admitted at 6 or more postnatal days; three on day 5 and one on day 4; all were discharged home.

\section{Risk factors for admission for jaundice}

The characteristics of babies admitted for jaundice differed significantly from the baseline characteristics of all term born babies in England $(\mathrm{p}<0.001)$; more babies admitted for jaundice were born at 37 weeks gestation (30.8\% vs $6.5 \%)$, male $(54.9 \%$ vs $51.1 \%)$, of low birth weight (1500-2499 g, 7.7\% vs $2.7 \%$ ), from multiple pregnancies $(3.4 \%$ vs $1.5 \%)$ and Asian $(17.9 \%$ vs $10.7 \%)$. We found that $35.7 \%$ of babies admitted for jaundice were born to multigravida mothers, $61.5 \%$ were delivered vaginally, 39.2\% were maternal blood group $\mathrm{O}+$ and $66.6 \%$ were maternal rhesus positive; however, due to the high 
Table 2 Primary reason for admission from hospital and home (2011-2013)

\begin{tabular}{lcr}
\hline Reason for admission & Babies (n) & $\%$ \\
\hline Hospital & & \\
\hline Respiratory disease & 30961 & 24.0 \\
\hline Infection & 22750 & 17.7 \\
\hline Missing & 20663 & 16.0 \\
\hline Other unspecified & 16675 & 13.0 \\
\hline Hypoglycaemia & 12925 & 10.0 \\
\hline Jaundice & 6950 & 5.4 \\
\hline Asphyxia & 3236 & 2.5 \\
\hline Poor feeding & 2703 & 2.1 \\
\hline Congenital abnormality & 1959 & 1.5 \\
\hline Cardiovascular disease & 1768 & 1.4 \\
\hline Other specified & 8198 & 6.4 \\
\hline Total & 128788 & \\
\hline Home & & \\
\hline Jaundice & 1082 & 22.3 \\
\hline Weight loss & 758 & 15.6 \\
\hline Respiratory disease & 753 & 15.5 \\
\hline Other unspecified & 554 & 11.4 \\
\hline Infection & 547 & 11.3 \\
\hline Poor feeding & 355 & 7.3 \\
\hline Missing & 217 & 4.5 \\
\hline Hypoglycaemia & 208 & 4.3 \\
\hline Asphyxia & 84 & 1.7 \\
\hline Other specified & 300 & 6.2 \\
\hline Total & & \\
\hline & & \\
\hline
\end{tabular}

level of missing data, these were not compared with ONS data.

\section{DISCUSSION}

In this large retrospective national study on term admissions, we found that the most common primary reason for admission was respiratory disease, accounting for a quarter of admissions, followed by infection, hypoglycaemia, jaundice and asphyxia. Jaundice was the most common reason for term admissions from home, responsible for a fifth of the admissions. Babies admitted for jaundice from home were admitted at a later age compared with those admitted from hospital. Compared with babies admitted for other reasons, those admitted for jaundice had a much shorter stay, and very few babies required HDC or IC; phototherapy and intravenous fluids were only administered to $80 \%$ and $30 \%$ of babies, respectively. These findings suggest that around two-thirds of babies may be appropriately cared for in a transitional care setting where they remain with their mothers, with maternity and neonatal support. Although the absolute numbers of kernicterus are small and cautious interpretation is necessary, the rate of kernicterus among those admitted from home was almost five times higher than those admitted from hospital. We speculate that this may be due to higher bilirubin levels at later presentation as a result of the lack of recognition by parents as midwives usually visit on the first and fifth postnatal days. Given the severity of the disability associated with kernicterus and the lifetime costs to the NHS, any intervention which can reduce the prevalence of this devastating condition needs to be carefully evaluated. ${ }^{8}$ We found that being born at 37 weeks gestational age, male, low birth weight, being one of a multiple birth or of Asian ethnicity increases the likelihood of requiring admission for jaundice. We note that the NICE-recommended treatment threshold for babies born at 37 weeks is lower than that for babies born at 38 weeks and above, which may have contributed to the relative excess of babies of 37 weeks gestation requiring admission. We recommend that a targeted assessment of feeding and jaundice is carried out between the first and fifth days, as recommended by NICE, ${ }^{9}$ and that parent education on jaundice and when to seek help is reinforced postnatally from day 1 , particularly for babies with risk factors.

\section{Strengths}

To our knowledge, this is the first study undertaken to investigate the reasons for term admissions to the neonatal unit in England. The main strength of this study is the large data set which includes admissions to all 163 neonatal units in England, and therefore, the findings can be generalised to national level. A further strength is the high level of completeness for the data fields required, which provided the necessary information to meet our objectives. Although data were not validated, these data are used daily as part of clinical care and to inform payments and commissioning, and therefore, we would expect a high level of accuracy.

\section{Limitations}

We acknowledge the limitations. Due to the retrospective nature of this study and utilisation of an established database, we were limited to the variables available on the EPR and NNRD. One major limitation was that the EPR permits only one primary reason for admission, determined by the clinician entering the data. As it is common for babies to present with jaundice, poor feeding, weight loss and hypoglycaemia at the same time, jaundice may well be a reason for admission, but not recorded as such. This may underestimate the rates of admission primarily for jaundice management. As these data are from the neonatal admission period and do not include post-discharge follow-up data, we appreciate that rate of kernicterus may be underestimated because kernicterus is not always diagnosed in the neonatal period. 


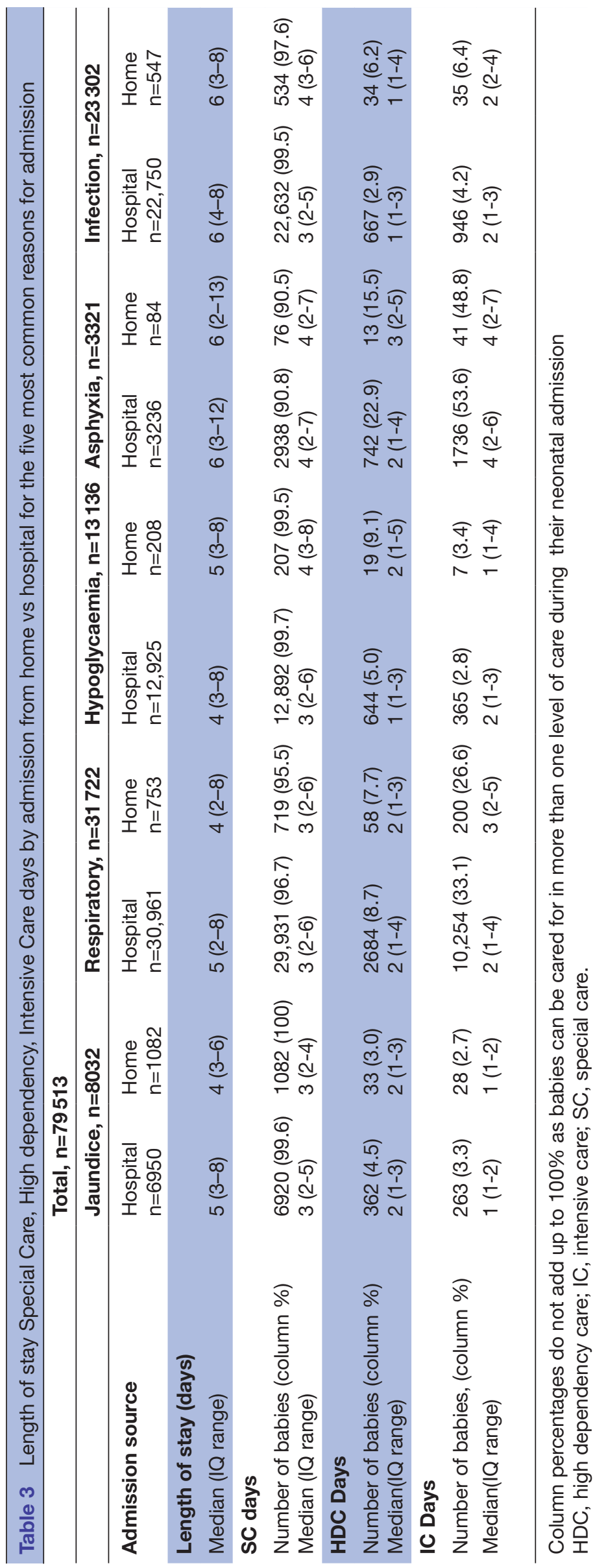

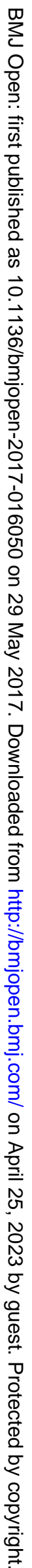


Table 4 Interventions and outcomes received by babies admitted for jaundice: home versus hospital

\begin{tabular}{|c|c|c|c|}
\hline & $\begin{array}{l}\text { Admitted from hospital, } \\
\mathrm{n}=6950\end{array}$ & $\begin{array}{l}\text { Admitted from home, } \\
n=1082\end{array}$ & Total, $\mathrm{n}=\mathbf{8 0 3 2}$ \\
\hline Admission postnatal age (days), median (IQR) & $1.7(0.9-2.9)$ & $3.9(2.6-5.3)$ & $1.9(0.9-3.4)$ \\
\hline Babies with missing data (\%) & 318 & 2 & 320 \\
\hline $\begin{array}{l}\text { Total days of phototherapy, \% of babies, median } \\
\text { (IQR) }\end{array}$ & $80.0 \%, 2(2-3)$ & $84.2 \%, 2(1-2)$ & $80.6 \%, 1(1-3)$ \\
\hline \multicolumn{4}{|l|}{ Received intravenous fluids } \\
\hline Number of babies & $2331(33.5 \%)$ & $304(28.1 \%)$ & 2635 (32.8\%) \\
\hline Duration of days, median (IQR) & $2(1-3)$ & $2(1-2)$ & $2(1-3)$ \\
\hline Exchange transfusion, number of babies (\%) & $110(1.6 \%)$ & $17(1.6 \%)$ & $127(1.6 \%)$ \\
\hline Kernicterus, number of babies & $4(0.06 \%)$ & $3(0.28 \%)$ & $7(0.09 \%)$ \\
\hline
\end{tabular}

Implications for clinicians and policymakers

Our findings demonstrate that two-thirds of term admissions to neonatal units for jaundice management may be potentially avoidable, provided that there are appropriate transitional care facilities which can keep mother and baby together. BLISS, a national charity for preterm babies, revealed that over a third of all units did not have dedicated accommodation for parents, and only five of the 29 neonatal IC units have enough accommodation to meet national standards. ${ }^{10}$ Unless extra resources are invested to support appropriately staffed models of care which avoid separation of mother and baby, admissions to neonatal units will continue to rise in England. Admission of term babies from within the hospital to the neonatal unit should be carefully considered. ${ }^{11}$ For babies admitted from the community, the decision to admit to the neonatal unit in preference to the paediatric or postnatal ward (where mother and baby are not separated) is influenced by local admission policies, bed capacity and resources, and the clinical condition of the baby; if deemed unstable or a possibility of requiring an exchange transfusion, this often lowers the threshold of admission to the neonatal unit. However, the finding that babies from home present later and have a higher rate of kernicterus (although small numbers) raises the question of whether these babies could have been identified and referred earlier in the community. Anecdotal evidence suggests that there is patchy implementation of transcutaneous bilirubinometers in the community and variation in the frequency of postnatal visits nationally, but formal evaluation is needed. Our findings support the recommendations of NICE regarding targeted assessment in the first days of life and the use of transcutaneous bilirubinometers. These findings reflect a need for effective identification, particularly of at-risk babies, and referral pathways from the community to the hospital.

\section{Future research and unanswered questions}

Further work is required to determine the variation in the provision of transitional care facilities nationally in the UK, uptake of the NICE guideline, particularly in the community, and to understand barriers to implementation. This will provide information of the work necessary to facilitate prompt referral pathways between the community and hospital. Further developments of transcutaneous bilirubinometers may enable production of models with improved accuracy, particularly at levels of bilirubin above $250 \mu \mathrm{mol} / \mathrm{L}$. Near-patient testing and monitoring of serum bilirubin levels in the community would prevent a significant number of hospital visits and unnecessary admissions.

\section{CONCLUSION}

Around two-thirds of babies admitted to neonatal care for the management of jaundice may be appropriately managed in a transitional care setting, avoiding separation of mother and baby. Babies at risk of jaundice who are cared for in the community may benefit from an additional postnatal visit around the third day of life to allow for early identification and management of jaundice. We recommend further work at a national level to examine provision and barriers to transitional care, referral pathways between primary and secondary care, and community postnatal care.

Acknowledgements We acknowledge the invaluable assistance of the Neonatal Data Analysis Unit, Yevgeniy (Eugene) Statnikov for data extraction and clinical teams from all contributing neonatal units (listed in Collaborators with the current lead clinician for each unit).

Collaborators Airedale General Hospital (Dr Matthew Babirecki), Alexandra Hospital (Dr Liza Harry), Arrowe Park Hospital (Dr Oliver Rackham), Barnet Hospital (Dr Tim Wickham), Barnsley District General Hospital (Dr Sanaa Hamdan), Basildon Hospital (Dr Aashish Gupta), Basingstoke \& North Hampshire Hospital (Dr Ruth Wigfield), Bassetlaw District General Hospital (Dr LM Wong), Bedford Hospital (Dr Anita Mittal), Birmingham City Hospital (Dr Julie Nycyk), Birmingham Heartlands Hospital (Dr Phil Simmons), Birmingham Women's Hospital (Dr Anju Singh), Bradford Royal Infirmary (Dr Sunita Seal), Broomfield Hospital, Chelmsford (Dr Ahmed Hassan), Calderdale Royal Hospital (Dr Karin Schwarz), Chelsea \& Westminster Hospital (Dr Mark Thomas), Chesterfield \& North Derbyshire Royal Hospital (Dr Aiwyne Foo), Colchester General Hospital (Dr Aravind Shastri), Conquest Hospital (Dr Graham Whincup), Countess of Chester Hospital (Dr Stephen Brearey), Croydon University Hospital (Dr John Chang), Cumberland Infirmary (Dr Khairy Gad), Darent Valley Hospital (Dr Abdul Hasib), Darlington Memorial Hospital (Dr Mehdi Garbash), Derriford Hospital (Dr Alex Allwood), Diana Princess of Wales Hospital (Dr Pauline Adiotomre), Doncaster Royal Infirmary (Dr Jamal S Ahmed), Dorset County Hospital (Dr Abby Deketelaere), East Surrey Hospital (Dr K Abdul Khader), Epsom General Hospital (Dr Ruth Shephard), Frimley Park Hospital (Dr Abdus Mallik), Furness General Hospital (Dr Belal Abuzgia), George Eliot Hospital (Dr Mukta Jain), Gloucester Royal Hospital (Dr Simon Pirie), Good Hope Hospital (Dr Phil Simmons), Great Western Hospital (Dr Stanley Zengeya), Guy's \& St Thomas' Hospital (Dr 
Timothy Watts), Harrogate District Hospital (Dr C Jampala), Hereford County Hospital (Dr Cath Seagrave), Hillingdon Hospital (Dr Michele Cruwys), Hinchingbrooke Hospital (Dr Hilary Dixon), Homerton Hospital (Dr Narendra Aladangady), Hull Royal Infirmary (Dr Hassan Gaili), Ipswich Hospital (Dr Matthew James), James Cook University Hospital (Dr M Lal), James Paget Hospital (Dr Ambadkar), Kettering General Hospital (Dr Patty Rao), King's College Hospital (Dr Ann Hickey), King's Mill Hospital (Dr Dhaval Dave), Kingston Hospital (Dr Vinay Pai), Lancashire Women and Newborn Centre (Dr Meera Lama), Leeds Neonatal Service (Dr Lawrence Miall), Leicester General Hospital (Dr Jonathan Cusack), Leicester Royal Infirmary (Dr Venkatesh Kairamkonda), Leighton Hospital (Dr Jayachandran), Lincoln County Hospital (Dr Kollipara), Lister Hospital (Dr J Kefas), Liverpool Women's Hospital (Dr Bill Yoxall), Luton \& Dunstable Hospital (Dr Jennifer Birch), Macclesfield District General Hospital (Dr Gail Whitehead), Manor Hospital (Dr Krishnamurthy), Medway Maritime Hospital (Dr Aung Soe), Milton Keynes General Hospital (Dr I Misra), New Cross Hospital (Dr Tilly Pillay), Newham General Hospital (Dr Imdad Ali), Norfolk \& Norwich University Hospital (Dr Mark Dyke), North Devon District Hospital (Dr Michael Selter), North Manchester General Hospital (Dr Nagesh Panasa), North Middlesex University Hospital (Dr Lesley Alsford), North Tyneside General Hospital (Dr Vivien Spencer), Northampton General Hospital (Dr Subodh Gupta), Northwick Park Hospital (Dr Richard Nicholl), Nottingham City Hospital (Dr Steven Wardle), Nottingham University Hospital (QMC) (Dr Steven Wardle), Ormskirk District General Hospital (Dr Tim McBride), Oxford University Hospitals, Horton Hospital (Dr Naveen Shettihalli), Oxford University Hospitals, John Radcliffe Hospital (Dr Eleri Adams), Peterborough City Hospital (Dr Seif Babiker), Pilgrim Hospital (Dr Margaret Crawford), Pinderfields General Hospital (Pontefract General Infirmary) (Dr David Gibson), Poole General Hospital (Prof Minesh Khashu), Princess Alexandra Hospital (Dr Caitlin Toh), Princess Anne Hospital (Dr Mike Hall), Princess Royal Hospital (Dr P Amess), Princess Royal University Hospital (Dr Elizabeth Sleight), Queen Alexandra Hospital (Dr Charlotte Groves), Queen Charlotte's Hospital (Dr Sunit Godambe), Queen Elizabeth Hospital, Gateshead (Dr Dennis Bosman), Queen Elizabeth Hospital, King's Lynn (Dr Glynis Rewitzky), Queen Elizabeth Hospital, Woolwich (Dr Olutoyin Banjoko), Queen Elizabeth the Queen Mother Hospital (Dr N Kumar), Queen's Hospital, Burton on Trent (Dr Azhar Manzoor), Queen's Hospital, Romford (Dr Wilson Lopez), Rosie Maternity Hospital, Addenbrooke's (Dr Angela D'Amore), Rotherham District General Hospital (Dr Shameel Mattara), Royal Albert Edward Infirmary (Dr Christos Zipitis), Royal Berkshire Hospital (Dr Peter De Halpert), Royal Bolton Hospital (Dr Paul Settle), Royal Cornwall Hospital (Dr Paul Munyard), Royal Derby Hospital (Dr John Mclntyre), Royal Devon \& Exeter Hospital (Dr David Bartle), Royal Hampshire County Hospital (Dr Katie Yallop), Royal Lancaster Infirmary (Dr Joanne Fedee), Royal Oldham Hospital (Dr Natasha Maddock), Royal Preston Hospital (Dr Richa Gupta), Royal Shrewsbury Hospital (Dr Deshpande), Royal Stoke University Hospital (Dr Alison Moore), Royal Surrey County Hospital (Dr Charles Godden), Royal Sussex County Hospital (Dr P Amess), Royal United Hospital (Dr Stephen Jones), Royal Victoria Infirmary (Dr Alan Fenton), Russells Hall Hospital (Dr Mahadevan), Salisbury District Hospital (Dr Nick Brown), Scarborough General Hospital (Dr Kirsten Mack), Scunthorpe General Hospital (Dr Pauline Adiotomre), South Tyneside District Hospital (Dr Rob Bolton), Southend Hospital (Dr Arfa Khan), Southmead Hospital (Dr Paul Mannix), St George's Hospital (Dr Charlotte Huddy), St Helier Hospital (Dr Salim Yasin), St Mary's Hospital, Isle of Wight (Dr Sian Butterworth), St Mary's Hospital, London (Dr Sunit Godambe), St Mary's Hospital, Manchester (Dr Ngozi Edi-Osagie), St Michael's Hospital (Dr Pamela Cairns), St Peter's Hospital (Dr Peter Reynolds), St Richard's Hospital (Dr Nick Brennan), Stepping Hill Hospital (Dr Carrie Heal), Stoke Mandeville Hospital (Dr Sanjay Salgia), Sunderland Royal Hospital (Dr Majd Abu-Harb), Tameside General Hospital (Dr Jacqeline Birch), Taunton \& Somerset Hospital (Dr Chris Knight), The Jessop Wing, Sheffield (Dr Simon Clark), The Royal Free Hospital (Dr V Van Sommen), The Royal London Hospital - Constance Green (Dr Vadivelam Murthy), Torbay Hospital (Dr Siba Paul), Tunbridge Wells Hospital (Dr Hamudi Kisat), University College Hospital (Dr Giles Kendall), University Hospital Coventry (Dr Kate Blake), University Hospital Lewisham (Dr Jauro Kuna), University Hospital of North Durham (Dr Mehdi Garbash), University Hospital of North Tees (Dr Hari Kumar), University Hospital of South Manchester (Dr Gopi Vemuri), Victoria Hospital, Blackpool (Dr Chris Rawlingson), Warrington Hospital (Dr Delyth Webb), Warwick Hospital (Dr Bird), Watford General Hospital (Dr Sankara Narayanan), West Cumberland Hospital (Dr Jason Gane), West Middlesex
University Hospital (Dr Elizabeth Eyre), West Suffolk Hospital (Dr lan Evans), Wexham Park Hospital (Dr Rekha Sanghavi), Whipps Cross University Hospital (Dr Caroline Sullivan), Whiston Hospital (Dr Laweh Amegavie), Whittington Hospital (Dr Wynne Leith), William Harvey Hospital (Dr Vimal Vasu), Worcestershire Royal Hospital (Dr Andrew Gallagher), Worthing Hospital (Dr Katia Vamvakiti), Yeovil District Hospital (Dr Megan Eaton), York District Hospital (Dr Guy Millman).

Contributors CB, SM, MU and JMR conceptualised the study, CB analysed the data and wrote the first draft. SM, MU and JMR contributed to revisions. CB, SM, MU and JMR have reviewed and approved the final manuscript.

Funding This research received no specific grant from any funding agency in the public, commercial or not-for-profit sector. Views expressed here are of the authors and not of the NHS or institutes affiliated.

Competing interests None declared.

Provenance and peer review Not commissioned; externally peer reviewed.

Data sharing statement The data that support the findings of this study are available from NDAU but restrictions apply to the availability of these data, which were used under license for the current study and so are not publicly available.

Open Access This is an Open Access article distributed in accordance with the Creative Commons Attribution Non Commercial (CC BY-NC 4.0) license, which permits others to distribute, remix, adapt, build upon this work non-commercially, and license their derivative works on different terms, provided the original work is properly cited and the use is non-commercial. See: http://creativecommons.org/ licenses/by-nc/4.0/

(C) Article author(s) (or their employer(s) unless otherwise stated in the text of the article) 2017. All rights reserved. No commercial use is permitted unless otherwise expressly granted.

\section{REFERENCES}

1. Crenshaw JT. Healthy birth practice \#6: keep mother and baby together - it's best for mother, baby, and breastfeeding. J Perinat Educ 2014;23:211-7.

2. BAPM. Categories of care secondary categories of care, 2011. http://www.bapm.org/publications/documents/guidelines/ CatsofcarereportAug11.pdf

3. Johnson L, Bhutani VK, Karp K, et al. Clinical report from the pilot USA Kernicterus Registry (1992 to 2004). J Perinatol 2009;29(Suppl 1):S25-45.

4. Burke BL, Robbins JM, Bird TM, et al. Trends in hospitalizations for neonatal jaundice and kernicterus in the United States, 1988-2005 Pediatrics 2009;123:524-32.

5. National Institute for Health and Care Excellence. Jaundice in newborn babies under 28 days secondary jaundice in newborn babies under 28 days, 2010. https://www.nice.org.uk/guidance/cg98

6. Neonatal Data Analysis Unit. Neonatal Data Analysis Unit. https:// www1.imperial.ac.uk/neonataldataanalysis/

7. Neonatal Data Analysis Unit. The UK National Neonatal Collaborative Agreement. 2012 https://www1.imperial.ac.uk/resources/30818E695AD7-4752-B13C-5EDAC2034D82/ukneonatalcollaborativecaldicott guardianagreementversion100712.pdf

8. Shapiro SM. Definition of the clinical spectrum of kernicterus and bilirubin-induced neurologic dysfunction (BIND). J Perinatol 2005;25:54-9.

9. Rennie J, Burman-Roy S, Murphy MS; Guideline Development Group. Neonatal jaundice: summary of NICE guidance. BMJ 2010;340:c2409.

10. BLISS. Families kept apart: barriers to parents' involvement in their baby's hospital care. 2016 http://www.bliss.org.uk/families-keptapart (accessed 1 Dec 2016).

11. Department of Health. Safer maternity care: next steps towards the national maternity ambition. 2016 https://www.gov.uk/government/ uploads/system/uploads/attachment data/file/560491/Safer Maternity_Care_action_plan.pdf 